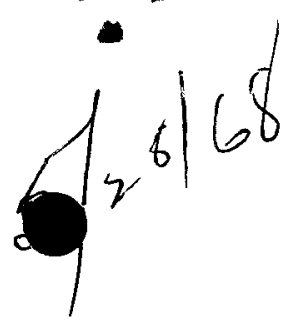

D. R. Wilkins

C. D. Sawyer

P. R. Hill
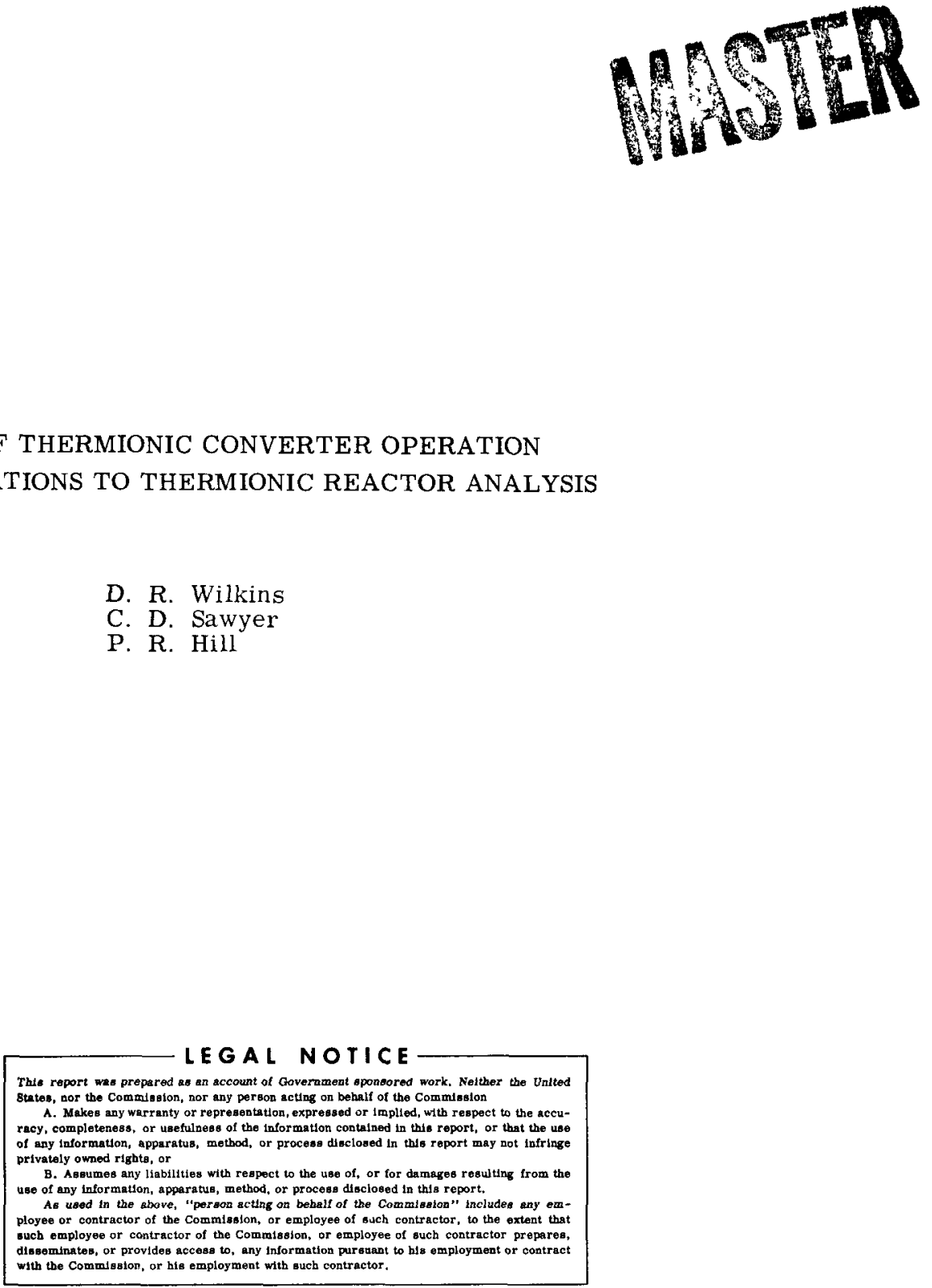

Nuclear Thermionic Power Operation

General Electric Company

Pleasanton, California

United States of America 


\section{DISCLAIMER}

This report was prepared as an account of work sponsored by an agency of the United States Government. Neither the United States Government nor any agency Thereof, nor any of their employees, makes any warranty, express or implied, or assumes any legal liability or responsibility for the accuracy, completeness, or usefulness of any information, apparatus, product, or process disclosed, or represents that its use would not infringe privately owned rights. Reference herein to any specific commercial product, process, or service by trade name, trademark, manufacturer, or otherwise does not necessarily constitute or imply its endorsement, recommendation, or favoring by the United States Government or any agency thereof. The views and opinions of authors expressed herein do not necessarily state or reflect those of the United States Government or any agency thereof. 


\section{DISCLAIMER}

Portions of this document may be illegible in electronic image products. Images are produced from the best available original document. 


\title{
THEORY OF THERMIONIC CONVERTER OPERATION \\ WITH APPLICATIONS TO THERMIONIC REACTOR ANALYSIS
}

\author{
D. R. Wilkins, C D. Sawyer, P R Hill
}

General Electric Company, Pleasanton, Calıfornia

United States of America

\begin{abstract}
Fundamental principles of molecular chemistry, statistical mechanics, and plasma physics are used to derive theoretical output current and efficiency characteristics of vapor thermionic converters The results are obtained in terms of basic physical parameters which describe the converter electrodes and interelectrode gas and are in good agreement with corresponding experimental measurements for a broad range of converter operating conditions

The theoretical formalism is employed to study the thermal and electrical performance characteristics of a nuclear thermionic fuel element it is shown that, with realistic axial fission profiles, fuel void fractions, and temperature limits, over-all fuel element efficiencies in the vicinity of 12 to $14 \%$ can be achieved.
\end{abstract}

\section{INTRODUCTION}

A theoretical description of thermionic converter operation is important in developing thermionic power plants. In particular, accurate converter theory greatly facilitates the design, testing, and evaluation of prototype converters, and is fundamental in analytical studies which lead to an optımum power plant design

An analytical description of the thermionic converter which ddequately fulfills these needs must incorporate three key features (1) be formulated in terms of basic data which characterizes the converter materials and operating conditions, (2) be applicable to the entire domain of practical thermionic converter operation, (3) yield results which are in agreement with experimental data.

The development of a useful analytic description of thermionic converter performance requires that due consideration be given to both electrode surface and interelectrode volume phenomena and to Schottky effects which occur at the electrode surface - interelectrode volume interfaces. Phenomena in each area have been separately considered in previous theoretical studies, many of which are cited in the literature $(1,2)$ These studies have served to isolate and to clarify many of the individual physical processes which are significant in thermionic converter operation. No attempt has been made, however, to combine and extend the previous analyses to provide a unified, practical theoretical description of thermionic converter operation

In this study, a unified theoretical description of thermionic converter performance characteristics is developed, programmed for digital computer studies, and the theoretical results compared with appropriate experimental data Significant features of the analysis are that it: (a) simultaneously accounts for the influence of surface and volume phenomena and Schottky effects on converter operation, (b) contains no restrictions concerning the "mode" of converter operation, (c) deals with the plasma sheath polarities self-consistently, (d) applies to converters with elevated collector temperatures, (e) provides for the determination of converter efficiency, and (f) is not restricted to Cs converters. Theoretical output current characteristics 
are obtained for a W emitter, Mo collector converter and exhibit good agreement with corresponding experımental characteristics for a broad range of emitter and Cs reservoir temperatures, and interelectrode spacings.

As an illustrative practical application, the theoretical formalism is employed to optimize the thermal and electrical performance characteristics of a nuclear thermionic fuel element (TFE). The influences of different design constraints on the optimized performance characteristics are discussed.

\section{THERMIONIC CONVERTER THEORY}

\section{VOLUME PHYSICS}

The neutral interelectrode plasma in a thermionic converter may be analyzed by using a previously derived set of transport differential equatıons. (3) Since plasma electron temperatures are nearly uniform, ${ }^{(4)}$ these equations may be written in the well-known approximate form:

$$
\begin{gathered}
\left(\mathrm{dJ} \mathrm{e}^{/ \mathrm{dx})=\left(\mathrm{d} J_{1} / \mathrm{dx}\right)}=\mathrm{e}\left(\nu_{1} \mathrm{n}-\beta_{r^{n}}{ }^{3}\right)\right. \\
J_{e}=-\mathrm{e}_{\mathrm{e}}\left[\theta_{\mathrm{e}}(\mathrm{dn} / \mathrm{dx})+\mathrm{nE}\right] ; J_{1}=-\mathrm{e}_{1}\left[\theta_{1}(\mathrm{dn} / \mathrm{dx})-\mathrm{nE}\right]
\end{gathered}
$$

where $\mathrm{J}_{\alpha}, \mu_{\alpha}$, and $\theta_{\alpha}$ are the current density, mobility, and temperature (in electron volts) for the electrons $(\alpha=\mathrm{e})$ and ions $(\alpha=1)$, respectively, $\mathrm{n}$ is the charged particle density: $\mathrm{E}$ is the electric field; $\nu_{1}$ is the ionization frequency, and $\beta_{r}$ is the three-body recombination coefficient.

The source terms in Eq. (1) describe a multistage volume ionization-recombination process. The recombination coefficient for Cs is assumed to have a form similar to that for hydrogen, $(6)$ since both atoms have a valence of unity and simılar binding energies for the higher excited states. The ionization frequency $\nu_{1}$ is computed from the recombination coefficient $\beta_{\mathrm{r}}$ to satisfy certain thermodynamic equilibrium requirements. (2)

The electron and ion mobilities in Eq. (2) are computed by using relations previously developed for three-component plasmas. ${ }^{2}$ Both charged particle and charged particle - neutral particle collisions are accounted for in the electron and ion mobilities. The former collisional processes are represented by a Coulomb interaction potential, while the latter are described in terms of effective hard sphere cross sections. The plasma electron temperature, which is assumed to uniform, must satisfy the energy balance equation

$$
q_{e 1}-q_{e 0}=J V_{P}-\left(J_{11}-J_{10}\right) V_{1}
$$

where $q_{e}$ is the electron kinetic energy flux; $v_{P}$ is the voltage drop across the interelectrode plasma, and the subscripts " 0 " and " $l$ " are used to denote a quantity evaluated at the emitter and collector edges of the plasma, respectively.

Equations (1) and (2) are integrated to yield, in terms of Jacobi elliptic functions, the charged particle density and electrostatic potential distributions in the interelectrode plasma. (2) The integration constants which arise and the electron kinetic energy fluxes $q_{e 0}$ and $q_{e l}$ are evaluated from sheath analyses as $d_{i}$ issed in $t_{1}$ following paragraphs. 
The electrostatic sheaths at the plasma-electrode interfaces are analyzed by writing electron and ion current and electron kinetic energy flux balances across the sheaths; 1 . e., between each electrode and the adjacent edge of the interelectrode plasma. The exact form of these balances for a given sheath depends upon its polarity, which is referred to here as accelerating or retarding If the sheath accelerates or retards, respectively, an electron traveling toward the collector. Electron and ion current and electron kinetic energy flux balances are given in Table 1 for accelerating and retarding emitter and collector sheaths. In this table, $\mathrm{J}_{\mathbf{M}}$ and $\mathrm{I}_{\mathbf{M}}$ are the electron and ion emission current densities, respectively, for the emitter (M-E) and collector $(M=C) ; V_{M}$ are the sheath voltage drops at the emitter $(M-E)$ and collector $(M-C)$ edges of the plasma; and $J_{r}$ and $I_{r}$ are the electron and ion random current densities, respectively, in the interelectrode plasma. Note that the sheath voltage drops are treated as negative and positive for accelerating and retarding sheaths, respectively The equations presented in Table 1 contain terms, derived from first order transport theory, to account for the non-Maxwellian, anisotropy of the plasma electron and ion distribution functions. These terms become appreciable if the net particle currents near the sheaths are comparable to the corresponding random currents.

The electron and ion emission current densities from the emitter and collector (Table 1) are governed by surface phenomena and Schottky effects The theoretical determination of these quantities is discussed in the following two sections.

\section{SURFACE PHYSICS}

The field-free, electron work function $\emptyset_{\mathbf{M}}$ of a substrate metal $(\mathbf{M})$ partially coated by an adsorbate film depends upon the substrate and adsorbate properties, the substrate temperature $\mathrm{T}_{\mathrm{M}}$, and the adsorbate reservour temperature $\mathrm{T}_{\mathrm{R}}$ In other words, for a specufied substrate and adsorbate: $\phi_{\mathbf{M}}-\phi_{\mathbf{M}}\left(\mathrm{T}_{\mathbf{M}}, \mathrm{T}_{\mathbf{R}}\right)$. The theoretical prediction of this relation for thermionic emitters $(M=E)$ and collectors $(M-C)$ is the objective of thermionic converter surface physics studies.

TABLE 1. Emitter and Collector Sheath Analyses

\section{ACCELERATING EMITTER SHEATH} $\left(V_{E} \leq 0\right)$
RETARDING EMITTER SHEATH $\left(V_{E} \geq 0\right)$

1. $\mathrm{J}_{\mathrm{e} 0}=\mathrm{J}_{\mathrm{E}} \exp \left(-\mathrm{V}_{\mathrm{E}} / \theta_{\mathrm{E}}\right)-\left(\mathrm{J}_{\mathrm{r} 0^{-1 / 2}} \mathrm{~J}_{\mathrm{e} 0}\right)$

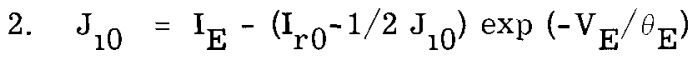

3. $\mathrm{q}_{\mathrm{e} 0}=2 \mathrm{~J}_{\mathrm{r} 0}\left(\theta_{\mathrm{E}}-\theta_{\mathrm{e}}\right)+\mathrm{J}_{\mathrm{e} 0}\left(\theta_{\mathrm{E}}+\theta_{\mathrm{e}}\right)$
ACCELERATING COLLECTOR SHEATH $\left(\mathrm{V}_{\mathrm{C}} \leq 0\right)$

RETARDING COLLECTOR SHEATH $\left(V_{C} \geq 0\right)$

$$
\begin{aligned}
& 1 \mathrm{~J}_{\mathrm{e} 1}=\left(\mathrm{J}_{\mathrm{r} 1}+1 / 2 \mathrm{~J}_{\mathrm{e} 1}\right) \exp \left(-\mathrm{V}_{\mathrm{C}} / \theta_{\mathrm{e}}\right)-\mathrm{J}_{\mathrm{C}} \\
& \text { 2. } \mathrm{J}_{11}-\left(\mathrm{I}_{\mathrm{r} 1}+1 / 2 \mathrm{~J}_{11}\right)-\mathrm{I}_{\mathrm{C}} \exp \left(-\mathrm{V}_{\mathrm{C}} / \theta_{\mathrm{C}}\right) \\
& \text { 3. } \mathrm{q}_{\mathrm{e} 1}=2 \mathrm{~J}_{\mathrm{C}}\left(\theta_{\mathrm{e}}-\theta_{\mathrm{C}}\right)+\mathrm{J}_{\mathrm{e} 1}\left(2 \theta_{\mathrm{e}}+\mathrm{V}_{\mathrm{C}}\right)
\end{aligned}
$$

Notes
1. Electron Current Balance
2. Ion Current Balance
3. Electron Kinetic Energy Flux Balance 
In this analysis, the recently developed Steiner-Gyftopoulos formalism ${ }^{(7)}$ is employed to determine the field-free, emitter and collector work functions. This formalism is an extension of earlier work ${ }^{(8)}$ and is based upon principles of molecular chemistry and statistical mechanics; it yields the relation $\phi_{M}=\phi_{M}\left(T_{M}, T_{R}\right)$ once a set of parameters which characterize the substrate and adsorbate are specified.

\section{SCHOTTKY EFFECTS}

The field-free work functions do not always prevail at the emitter and collector electrodes in a thermionic converter In particular, if the emitter sheath is accelerating or the collector sheath is retarding, the electric field at the corresponding electrode surface depresses the effective electrode work function as shown in Fig. 1

The effective lowering of an electrode work function by an imposed electric field (Fig 1) was first analyzed by Schottky who obtanned

$$
\Delta \phi_{\mathbf{M}}=\phi_{\mathbf{M}}-\phi_{\mathbf{M}}^{\prime}-\sqrt{\left[\mathrm{e} /\left(4 \pi \epsilon_{0}\right)\right] \mathrm{E}_{\mathbf{M}}}
$$

where $\phi_{M}$ and $\phi^{\prime} M$ are the field-free and effective work functions of electrode $M$, respectively, e is the electronic charge, $\epsilon_{0}$ is the vacuum permittivity, and $E_{M}$ is the magnitude of the electric field existing at the surface of electrode $M$

Hansen $(9,10)$ employed Eq. (4) to demonstrate the importance of Schottky effects in thermionic converters The analyses were performed for limited domains of converter operation, and they cannot readily be extended to apply to the broad range of converter operating conditions under present consideration Therefore, an alternate approach to the analysis of Schottky effects in thermionc converters is utilized here significant features of the present analysis are that it is mathematically simple, and yet can be expected to yield reasonably accurate results for the entire range of converter operating conditions of practical interest

In applying Eq. (4) to the present problem, some uncertainty exists concerning the electric field, $E_{M}$, since the exact potential distribution within the electrostatic sheath is unknown Generally, the sheath voltage drop occurs within several plasma electron Debye lengths of the electrode. Hence, it is reasonable to expect that the electric field at the electrode surface can be accurately approximated by

$$
\mathrm{E}_{\mathbf{M}}=\mathrm{k}_{\mathrm{S}} \quad \mathrm{V}_{\mathbf{M}} / \mathrm{L}_{\mathbf{M}}
$$

where $\mathrm{L}_{\mathrm{M}}$ is the electron Debye length at the edge of the plasma adjacent to the sheath; and $k_{\mathrm{s}}$ is a dimensionless constant of order unity

Equations (4) and (5) are used in this analysis to describe the Schottky reduction of the emitter work function caused by an accelerating emitter sheath, and of the collector work function caused by a retarding collector sheath The field-free work functions $\phi_{M}(M=E, C)$ are computed from surface physics considerations, Eq (4) and (5) then yield the effective work functions $\phi_{M}^{\prime}(\mathrm{M}-\mathrm{E}, \mathrm{C})$ When the emitter sheath is retarding or the collector sheath is acce1erating, no Schottky correction is applied to the corresponding electrode work function; 1 e. , $\phi^{\prime} \mathbf{M}-\phi_{\mathbf{M}}$ 
Once the effective work function $\phi^{\prime}{ }_{M}$ is determined, emission current densities of electrons and ions from a thermionic converter electrode $M(M=E, C)$ follow directly from the Richardson and Saha-Langmuir equations, respectively In particular

$$
\begin{aligned}
& \mathrm{J}_{\mathbf{M}}=\mathrm{A} \mathrm{T}_{\mathbf{M}}^{2} \exp \left(-\sigma^{\prime}{ }_{\mathrm{M}} /{ }_{\mathrm{M}}\right), \quad{ }^{\theta}{ }_{\mathrm{M}}=\mathrm{kT}_{\mathrm{M}} / \mathrm{e} \\
& \mathrm{I}_{\mathrm{M}}-\operatorname{ep}_{\mathrm{g}}\left(2 \pi \mathrm{m}_{\mathrm{g}} \mathrm{e}{ }_{\mathrm{M}}\right)^{-1 / 2}(1 / 2) \exp \left[-\left(\mathrm{V}_{\mathrm{l}}-\mathrm{o}_{\mathrm{M}}^{\prime}\right) /{ }_{\mathrm{M}}\right]
\end{aligned}
$$

where $A$ is the Richardson constant and $m_{g}$ is the mass of the adsol bate atoms Equation (7) is an approximate form of the Saha-Langmuir equation which is valid provided the surface ionization probability is small compared to unity 'This condition is always fulfilled for practical thermionic converter operating conditions

\section{THERMIONIC CONVERTER PERFORMANCE}

The thermionic converter output voltage $\mathrm{V}$ for a specified output cur rent density $\mathrm{J}$ is obtained by summing the voltage drops between the emitter and collector Feimi levels Thus,

$$
\mathrm{V}-\mathrm{o}_{\mathrm{E}}^{\prime}+\mathrm{V}_{\mathrm{E}}-\mathrm{V}_{\mathrm{P}}+\mathrm{V}_{\mathrm{C}}-\mathrm{o}_{\mathrm{C}}^{\prime}
$$

The several terms in this relation follow directly from the preceding analyses

The intrinsic efficiency $\eta_{1}$ of a thermionic converter is defined as the efficiency in the absence of electrode, lead, and structural support losses This efficiency is independent of detailed converter design considerations and is given by

$$
\eta_{1} \quad P\left(Q_{e}+Q_{1}+Q_{1}+Q_{g}\right)
$$

where $P=J V$ is the output powel density, and $Q_{e}, Q_{1}, Q_{1}$, and $Q_{g}$ are the heat fluxes I emoved from the emitter by electrons, ions, radiation, and gas conduction, respectively The first three heat fluxes are given by

$$
\begin{aligned}
& Q_{e}-J_{e 0}\left(o_{E}^{\prime}+V_{E}\right)+q_{e 0} \\
& Q_{1}-{ }^{-} J_{10}\left(\phi_{E}^{\prime}+V_{E}\right)+J_{10} V_{1} \\
& Q_{r}=\sigma\left(\epsilon_{E} T_{E}^{4}-\epsilon_{C} T_{C}^{4}\right)
\end{aligned}
$$

where $\sigma$ is the Stefan-Boltzmann constant, and $\epsilon_{E}$ and $\epsilon_{C}$ are effective emissivities An expression for the interelectrode gas conduction term $Q_{g}$ for Cs has been given by Kitrilakis, et al (11) Note that $\mathrm{Eq}$ (9) is readily modified to compute device efficiencies for specific converter designs by including terms to account for electrode, lead, and structural support losses

\section{COMPARISON OF THEORY WITH EXPERIMENT}

\section{NUMERICAL CALCULATIONS}

A digital computer code has been written which incorporates the volume physics, surface physics, and Schottky effect analyses described here The code input includes the physical parameters which characterize the converter electrodes and interelectrode gas and the converter operating conditions. With this input, the code obtains iterative solutions of the equations which 
describe the surface and volume phenomena. In these computations, self-consistent sheath polarities are determined for each set of converter operating conditions, Schottky corrections are applied to the electrode work functions if appropriate The code returns the converter output current and efficiency characteristics and other operating parameters of practical interest.

\section{EXPERIMENTAL DATA}

The experimental data chosen for comparison is a set of output current characteristics obtained by $\mathrm{TECO}^{(2)}$ for a thermionic converter with a heat-treated $\mathrm{W}$ emitter and polycrystalline Mo collector. The characteristics encompass a broad range of converter operating conditions and are divided into three groups to exhibit the effects of independent variations in emitter temperature, Cs reservoir temperature, and interelectrode spacing (Fig 2).

\section{THEORETICAL INPUT PARAMETERS}

The input parameters used to compute output current characteristics for comparison with the experimental data are presented elsewhere. ${ }^{(2)}$ It is shown that the values employed for the key parameters are in satisfactory agreement with the avallable, but sometimes limited and inapplicable, independent data

\section{THEORETICAL RESULTS}

The theoretical output current characteristics in Figure 2 are computed for the indicated operating conditions by using the techniques and data reported here The results are in excellent qualitative and good quantıtative agreement with corresponding experimental measurements for the entire range of converter operating conditions Even better agreement could be anticipated, however, with slight adjustments of certain input parameters.

Note that both the computed and measured output current characteristics in Fig. 2 exhibit an abrupt rise in the output current density as the output voltage is decreased and the converter enters the ignited mode of operation. The theory of this transition from the extinguished to the ignited mode has not been previously presented.

Another significant feature of the theoretical results in Fig 2 is the nonsaturation of certain output current characteristics at low output voltage, e.g., curve 4 of Fig. 2a. The significant increase in the output current density as the output voltage is decreased is due to Schottky effects and ion currents at the emitter surface.

\section{THERMIONIC FUEL ELEMENT ANALYSIS}

In this section the theoretical formalism is employed in an investigation of the thermal and electrical performance characteristics of a nuclear TFE. The influence of fuel center and emitter temperature constraints on the performance of the fuel element is shown.

\section{FUEL ELEMENT DESCRIPTION}

A nuclear TFE is shown in Fig. 3; it consists of $\mathrm{N}$ series-connected cells contained within an insulated sheath tube and serviced by a single cesium reservoir Each cell is loaded with an 
idential volume fraction of $\mathrm{UO}_{2}$ fuel, and receives a fraction $\mathrm{f}_{\mathrm{n}}(1 \leq \mathrm{n} \leq \mathrm{N})$ of the total TFE thermal power. In general, the $f_{n}$ 's are unequal because of the nonuniformaties in the axial fission profile. The fuel element is cooled externally be a liquid metal coolant.

\section{COMPUTATIONAL PROCEDURE}

The operating state of a multicell TFE is completely defined by specifying the thermal power, axial power distribution, electrical current, cesium reservoir temperature, coolant inlet temperature, and over-all coolant temperature rise. Figure 4 shows the logical structure of a digital computer program which employs this information to yield a cell-by-cell and over-all description of the TFE electrical and thermal performance characteristics. This program incorporates the thermionic converter analysis as a subroutine. Other major subroutines describe heat transfer within the fuel-emitter body, through the tri-layer collector-insulatorsheath structure, and from the TFE sheath to the liquid metal coolant

\section{TFE PERFORMANCE CHARACTERISTICS}

A 12 -cell TFE with a coolant inlet temperature of $800^{\circ} \mathrm{K}$ and over-all coolant temperature rise of $100^{\circ} \mathrm{K}$ is discussed. The axial fission profile, which is typical for a small, fast spectrum, thermionic reactor, is shown in Table 2 Note that this profile exhibits a peak-to-minimum fission ratio of 1.2 to 1.0 .

TABLE 2 Axial Fission Profile

\begin{tabular}{|c|c|c|c|}
\hline Cell, n & Fractional Power, $\mathrm{f}_{\mathrm{n}}$ & Cell, n & Fractional Power, $\mathrm{f}_{\mathrm{n}}$ \\
\hline 1 & 0.08020 & 7 & $\begin{array}{ll}0 & 09071\end{array}$ \\
\hline 2 & 0.07434 & 8 & 008858 \\
\hline 3 & 0.07933 & 9 & 0.08463 \\
\hline 4 & 008502 & 10 & $0 \quad 07945$ \\
\hline 5 & 0.08899 & 11 & 0.07490 \\
\hline 6 & 0.09099 & 12 & 0.08288 \\
\hline
\end{tabular}

A summary of the performance characteristics of the 12 -cell fuel element for a thermal input power $\mathrm{P}_{\mathrm{th}}$ of $14.9 \mathrm{kWt}$ is given in Fig 5. Shown versus electrical current density are: (a) the optimum cesium reservoir, $\mathrm{T}_{\mathrm{r}}^{\text {opt }}$, (b) the cesium optimized electrical power, $\mathrm{P}_{e}$, (c) the highest prevalling emitter temperature, $\mathrm{T}_{\mathrm{e}}^{\mathrm{max}}$, and (d) the highest prevalling central fuel cavity temperature, $T_{f}^{\max }$. The latter quantity is shown for several fuel vold fractions, V. Note that the maximum electrical output which can be achieved for the $149 \mathrm{kWt}$ thermal input is $2.24 \mathrm{kWe}$; which corresponds to an over-all TFE efficiency of $15 \%$

The influence of design constraints on the fuel and emitter temperatures is readily deduced from Fig. 5. Suppose, for example, that the cell emitter temperatures are to be operated below $2073^{\circ} \mathrm{K}$. This temperature restricts the permissible output current densities to values in excess of $10.6 \mathrm{~A} / \mathrm{cm}^{2}$. The maximum electrical output consistent with this constraint is $2.02 \mathrm{kWe}$ which corresponds to a TFE efficiency of $13.5 \%$ For a specified fuel vold fraction, constraints on the central fuel cavity temperature may be applied in a like manner

Plots of the type shown in Fig. 5 have been computed for other TFE thermal power levels. For each thermal power, an optımum electrical output exists for a given set of design constraints. 
Figure 6 shows the fully optimızed TFE electrical output versus thermal input for different design limitations on the emitter and central fuel cavity temperatures. In Fig. 6 Curve 1 represents an upper limit which is achieved in the absence of temperature limitations. Curves 2 through 5 reflect the influence of both a $2073^{\circ} \mathrm{K}$ emitter temperature limit and a $2850^{\circ} \mathrm{K}$ central fuel cavity temperature limit on the results for different fuel vold fractions. Note that when such temperature limits are imposed the electrical output does not increase monotonically with thermal input.

The results shown in Fig. 6 indicate that, with realistic axial fission profiles, fuel void fractions, and temperature limitations, TFE efficiencies in the vicinity of 12 to $14 \%$ can be achieved. The determinations of over-all thermionic reactor efficiencies require further optimizations involving fuel lodding fractions and radial fission distributions, and is beyond the scope of this paper. Results of the type presented in Fig. 6, however, are important in such determinations.

\section{SUMMARY AND CONCLUSIONS}

A unfied theoretical description of thermionic converter performance characteristics is presented. The analysis simultaneously accounts for the influence of surface phenomena, volume phenomena, and Schottky effects on converter operation; and yields theoretical output current characteristics which are in good agreement with experment data for a very broad range of converter operating conditions The analysis has practical applications for converter physics studies, converter performance evaluatıons, and thermınıc power plant design

The electrical and thermal performance character istics of a 12 -cell nuclear thermionic fuel element are described. It is shown that, with realistic axid fission profiles, fuel vold fractions. and fuel and emitter temperature limitations. TFE efliciencies in the 12 to $14 \%$ range can be realized.

\section{REFERENCES}

1. Bullıs, R. H., et al., Therm. Conv. Spec Conf , San Diego, Calif , October 1965.

2. Wilkins, D. R., to be published, J Appl Phys , (1968)

3. Wilkins, D. R. and Gyftopoulos, E P , Proc. Int Conf on Therm Elec, Power Gen., London, England, September 1965.

4. Reichelt, W. H, Proc. Int. Conf on Therm. Elec Power Gen, London, England, September 1965.

5. Wilkıns, D. R. and Gyftopoulos, E P . Proc. Therm. Conf., San Diego, Calıf., October 1965.

6. Hinnov, E and Hirschberg, J. G, Phys Rev 125 (1962) 795-801.

7. Steiner, D. and Gyftopoulos, E. P., Proc. 27th Ann. Phys. Elec. Conf., Cambridge, Mass., March 1967.

8 Levine, J. D and Gyftopoulos, E. P , Surface Science, 1 (1964) 171-193, 225-241, 349-360.

9. Hansen, L. K, Proc. 25th Ann. Phys. Elec. Conf, Cambridge, Mass., March 1965

10. Hansen, L. K., Proc. Therm. Conv. Spec. Conf , San Diego, Calıf., October 1966.

11. Kitrılakıs, S. and Meeker, M., J. Ad̉v. Energy Conv., 3 (1963) 59-68.

12. Howard, R., Thermo Electron Corp., Waltham, Mass , private communication, March 1966 


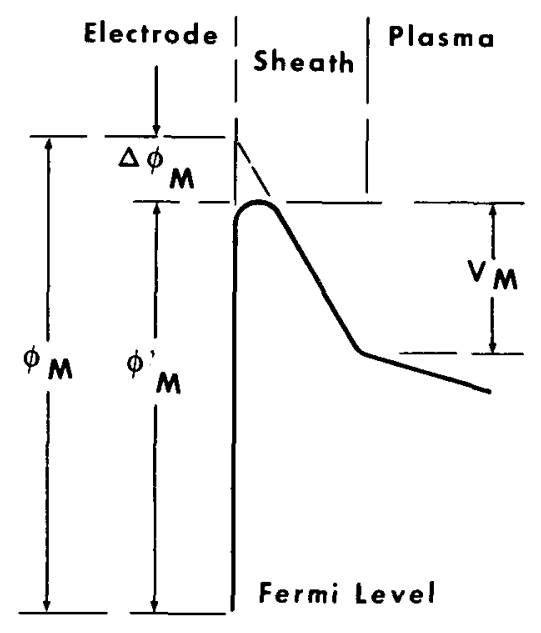

FIGURE 1. Influence of Electrostatic Sheath on Work Function of Thermionic Converter Electrode 

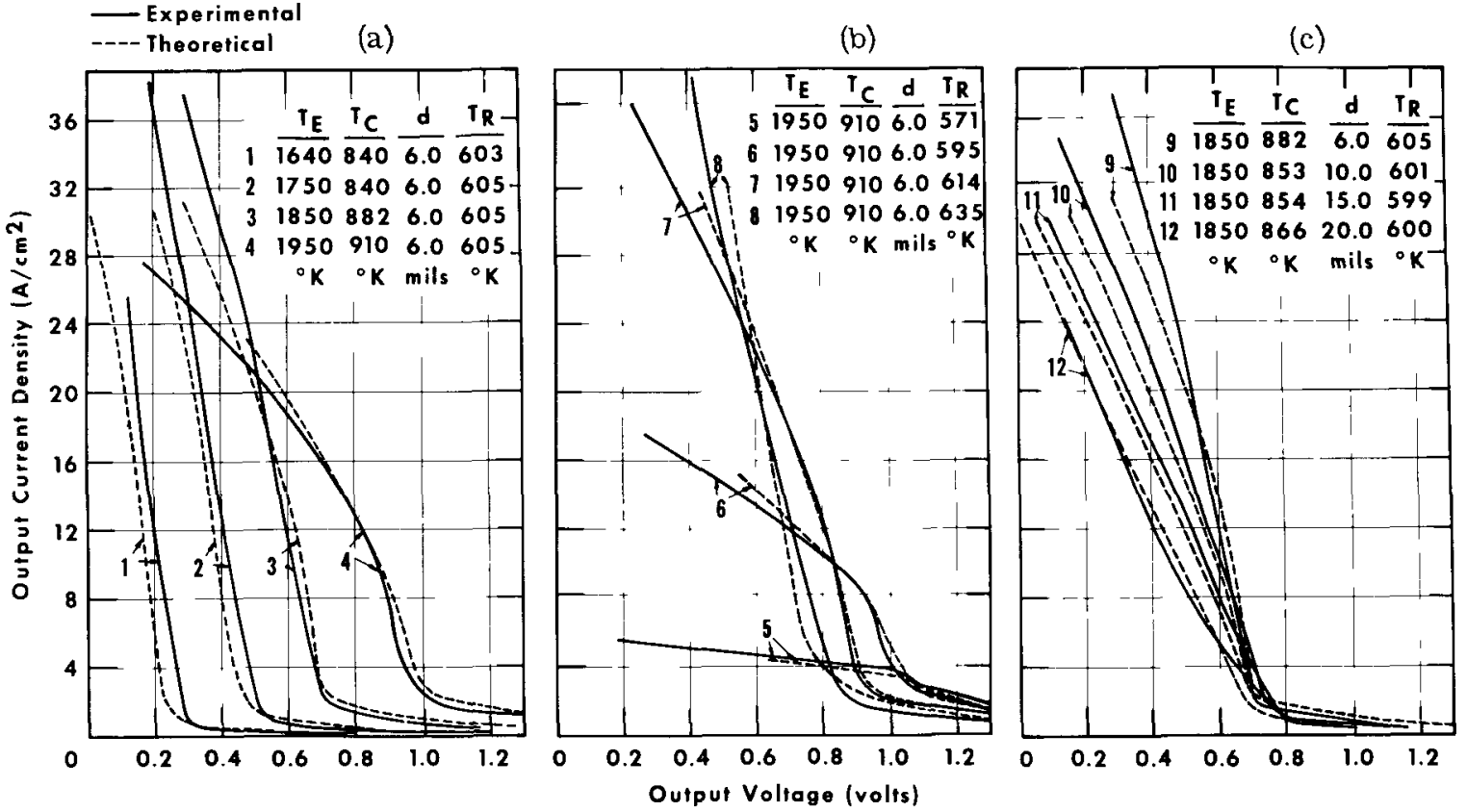

FIGURE 2. Comparison of Computed and Measured ${ }^{(24)}$ Output Current Characteristics For Several (a) Emitter Temperatures, (b) Cesium Reservoir Temperatures, and (c) Interelectrode Spacings 

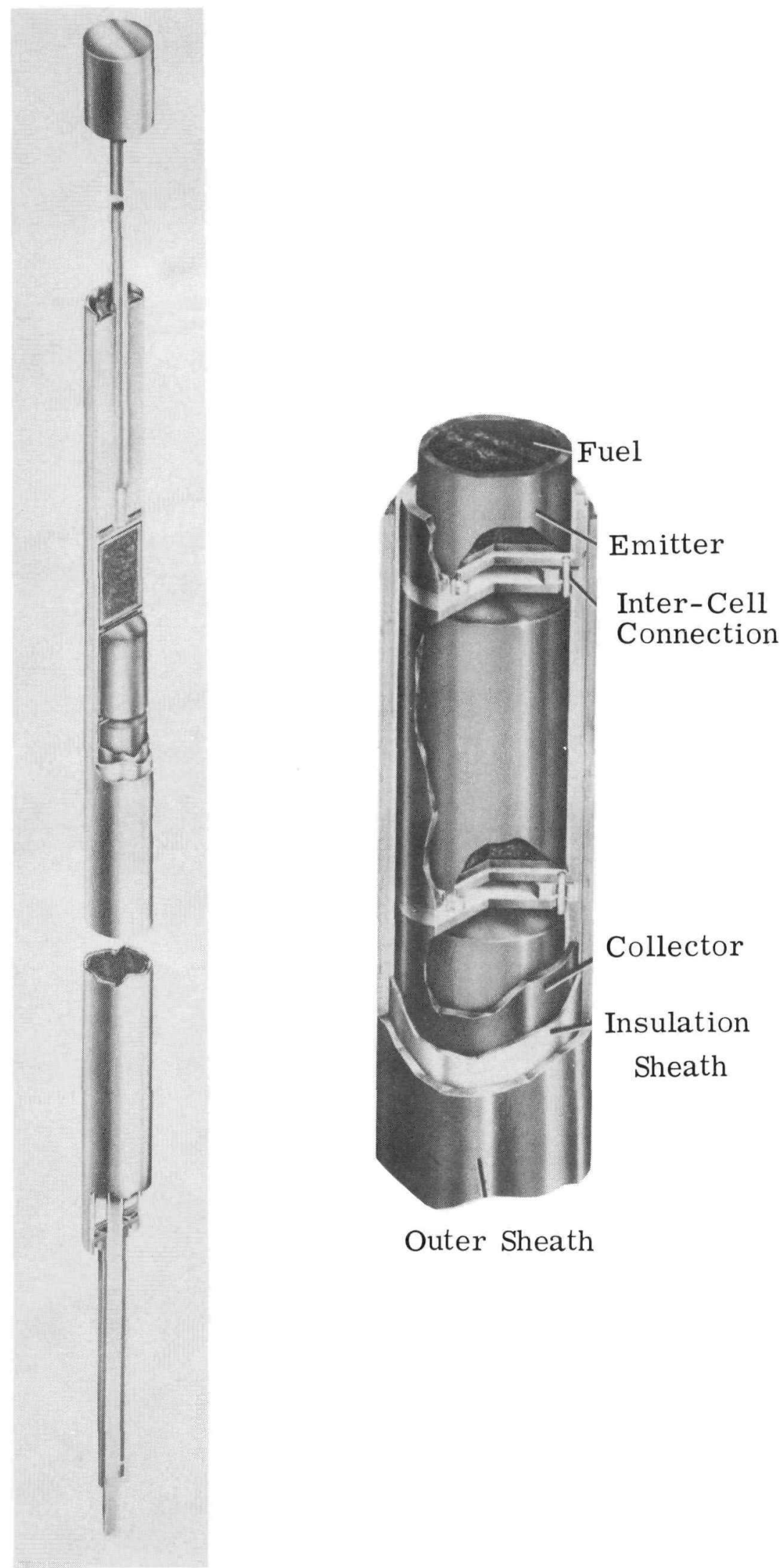

FIGURE 3. Nuclear Thermionic Fuel Element 


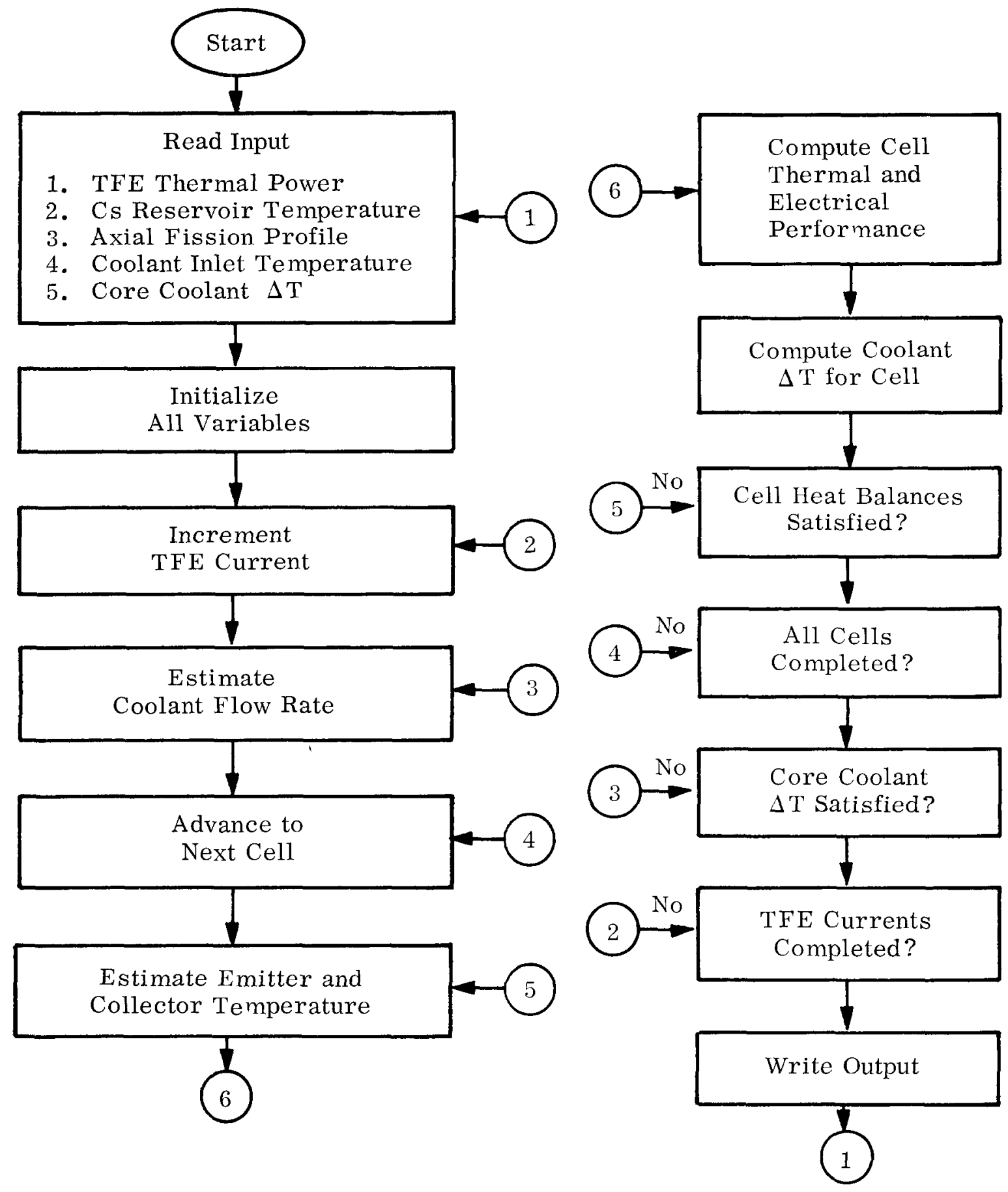

FIGURE 4. Logical Flow Diagram for TFE Performance Computation 


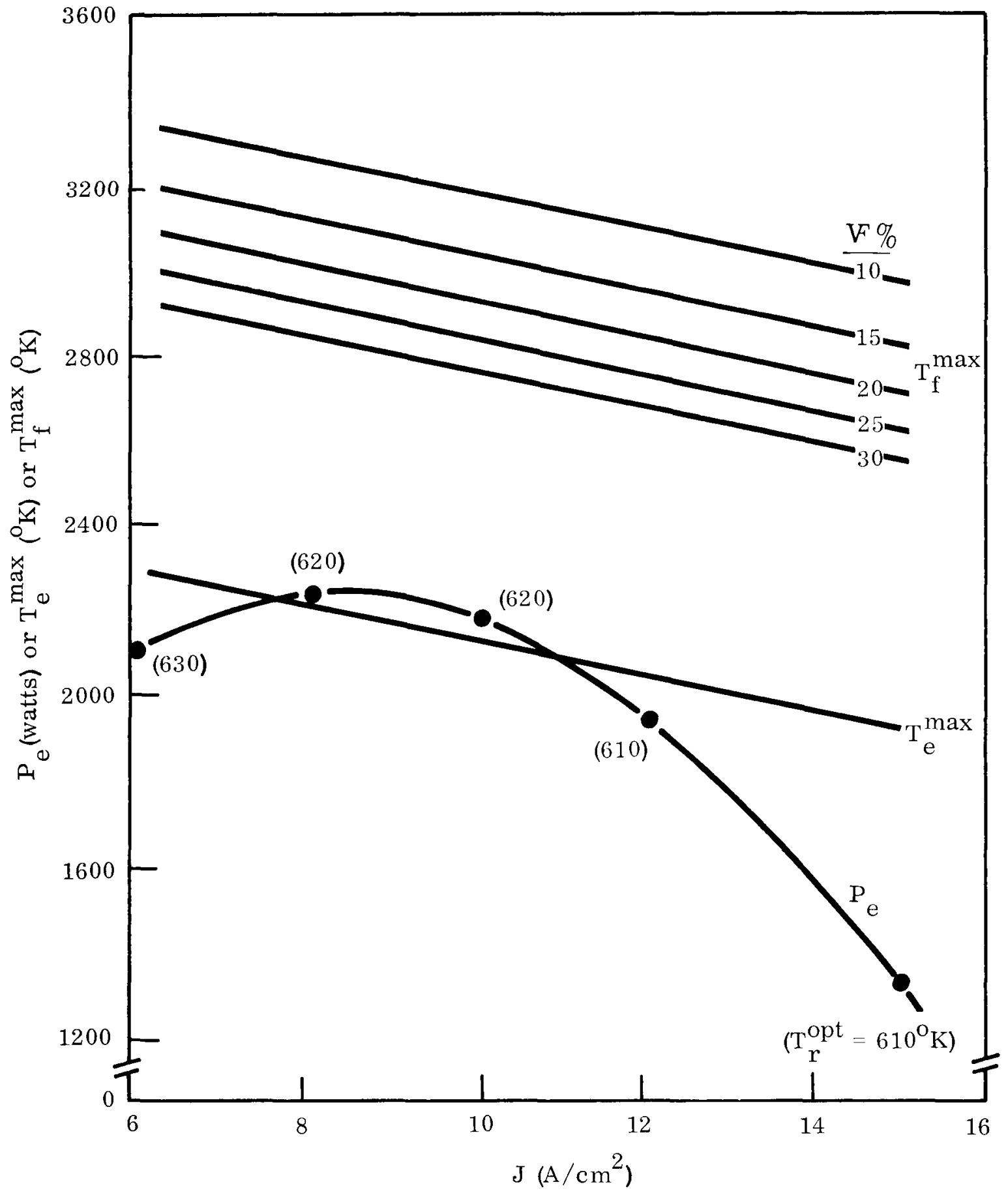

FIGURE 5. TFE Performance Characteristics for $\mathrm{P}_{\text {th }}=14.9 \mathrm{~kW}$ 


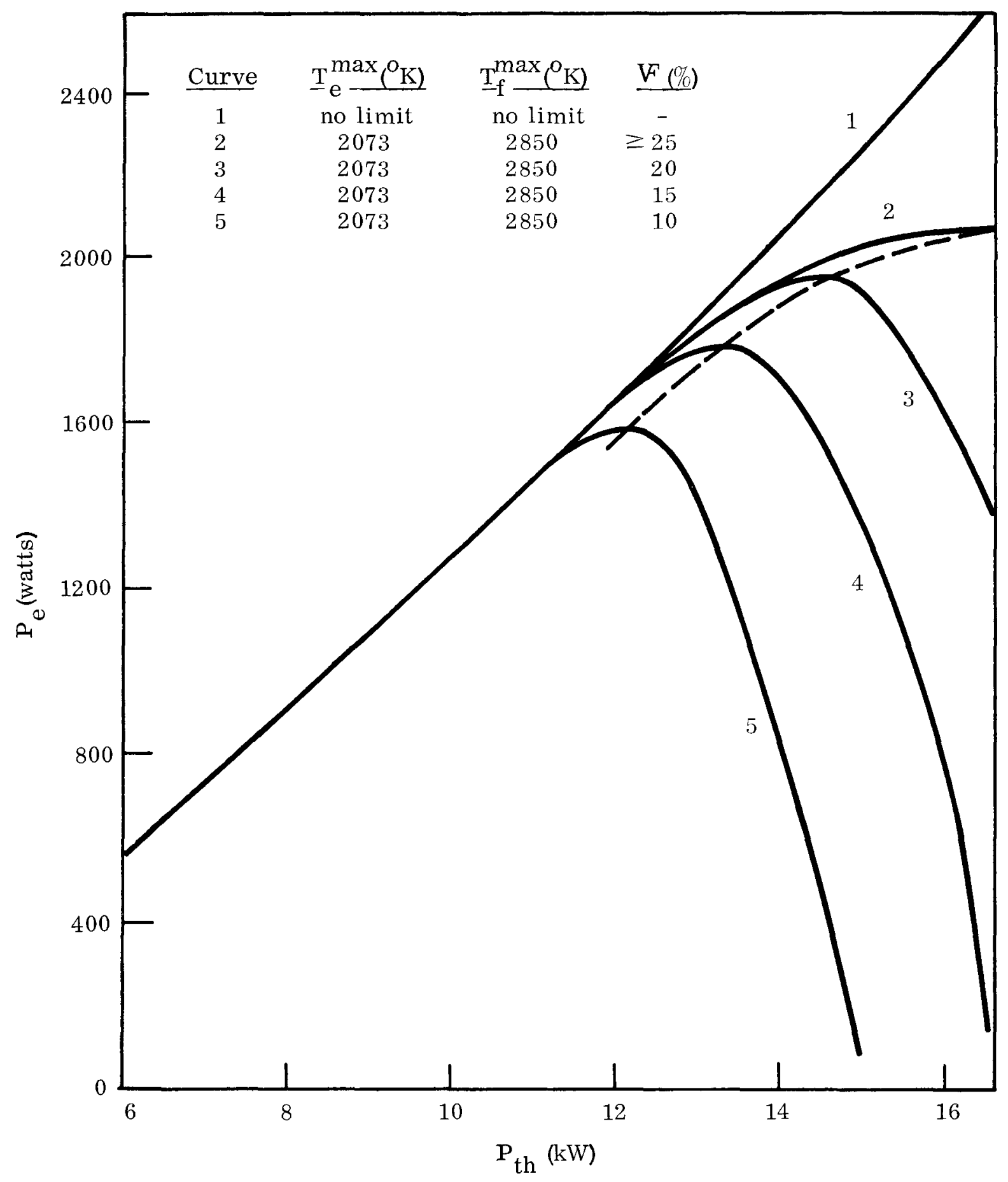

FIGURE 6. Fully Optimized TFE Performance Characteristics 